\title{
Effect of Intradialytic Hemodialysis Exercises on Fatigue and Leg cramps
}

\author{
Asmaa Hassan Albadry ${ }^{1}$, Sahra Zaki Azer ${ }^{2}$, Nayel Abd Elhamed ${ }^{3} \&$ Neama Mamdouh Mostafa ${ }^{4}$ \\ 1. Demonstrator in Medical Surgical Nursing, Faculty of Nursing, Sohag University, Egypt. \\ 2. Assistant Professor of Medical - Surgical Nursing, Faculty of Nursing, Assiut University, Egypt. \\ 3. Assistant Professor of Medical Department- Faculty of Medicine, Sohag University, Egypt. \\ 4. Lecturer of Medical, Surgical Nursing, Faculty of Nursing, Assiut University, Egypt.
}

\begin{abstract}
Background: Hemodialysis is an ongoing process where patients experience complications such as hypotension, muscle cramps, fatigue and nausea during the procedure. Aim: To evaluate the effect of implementing intradialytic hemodialysis exercises program on fatigue and leg cramps. Subjects and methods: Pre/posttest was utilized in this study. it was conducted in dialysis unit at Sohag University Hospital, A sample of 60 patients who undergoing hemodialysis with fistula (peripheral vascular access), with age 18-65 years old. four tools were used: Tool(I): Structured Interview Questionnaire sheet, Tool (II):Cramp questionnaire chart and visual analogue scale : Pre/post test (after 2 months) Tool (III) : Fatigue severity scale and Tool (IV): Intradialytic exercise. Results. The mean age of the patients was $43.80 \pm 12.089$ (range 18- 65). More than half of patients (58.3\%) experienced muscle cramps in both the legs. As regard muscle involved in cramps, majority of patients $(83.3 \%)$ experienced muscle cramps in gastrocnemius muscle. Conclusion: The findings of the study revealed that there were statistical significance differences as regard cramps questionnaire chart, visual analogue scale and fatigue severity scale pre \&post intradialytic exercises. Recommendations: Intradialytic exercises can be adapted as a procedure to the patients undergoing hemodialysis.
\end{abstract}

\section{Keywords: Fatigue, Hemodialysis, Intradialytic Exercises \& Muscle Cramps.}

\section{Introduction}

Chronic renal failu End-stage renal disease (ESRD) is emerging as a
major health problem in the developing countries. Chronic kidney disease involves progressive, irreversible destruction of the nephrons in both kidneys leads to accumulation of toxins and fluids creating fluid and electrolyte imbalances and must be treated with renal replacement therapy for the survival ( Paluchamy \& Vaidyanathan, 2018)

In Egypt, the estimated annual incidence of ESRD is around 74 per million and the total prevalence of patients on haemodialysis is 264 per million. The main causes of ESRD in Egypt, other than diabetic nephropathy, include hypertensive kidney disease, chronic glomerulonephritis, and obstructive uropathy (El-Arbagy et al., 2016).

Hemodialysis (HD) is a procedure used to manage patients with ESRD through using artificial kidney machine to substitute the failed kidneys' functions (Caplin et al., 2017) . HD, is considered one of the principle renal replacement therapies among patients with ESRD, it is a time-consuming procedure that precedes around 3 to 5 hours a day, 2 or 3 times per week (Park, \& Jung, 2017).In this process in addition to removing waste materials, some necessary products are added to the blood (Wanek et al., 2015) Unpleasant side- effects of hemodialysis such as hypotension, muscle cramps, fatigue, nausea and vomiting could happen during the process (Hall et al., 2015).

Fatigue is defined as persistent and extreme tiredness that leads to mental or physical exhaustion or both with a prevalence ranging from $60 \%$ to $97 \%$. It is associated with lower quality of life, and lower survival rates (Horigan et al., 2013). Patients who suffer from post dialysis fatigue need more than three hours of rest after each session to recover. Hence, the management of fatigue is an important clinical priority for health care providers (Artom et al., 2014).

Muscle cramps, defined as involuntary muscle contraction accompanying with severe stretched pain, most commonly associated with HD. Around $33 \%$ to $86 \%$ of patients receiving HD have experienced muscle cramps which begin with very painful muscle twitches causing the patient hardly to move. Unluckily, this can happen during HD treatment. Usually the muscle cramp can lead to termination of dialysis session before the planned time, causing a less effective treatment. There are many factors that may lead to muscle cramps in patients with ESRD receiving dialysis as a decreased fluid volume in the body, decreased blood pressure, fluid and electrolyte imbalance, decreased sodium level, tissue hypoxia and hypomagnesaemia

(Damasiewicz \& Polkinghorne, 2017) 
Intradialytic exercise (IDE) is defined as exercise training performed during the hemodialysis (HD) session to increase the patient's strength and endurance, and hence targeting various physiological and psychosocial parameters. The nature of the IDE varies from resistance to aerobic exercise and stretching, with different equipment used corresponding to the type of exercise. IDE has demonstrated a positive effect on the overall health and hospitalization rate of HD patients. (Salhab et al., 2019)

\section{Significance of the study}

Total number of hemodialysis patients weekly are 60 cases at Sohag university hospital . From the researcher's clinical experience has been observed that fatigue and leg cramps is the most common symptom among patients undergoing hemodialysis. Therefore this study was carried to determine the effect of intradialytic exercises on minimize the fatigue and leg cramps among patients undergoing hemodialysis.

\section{Aim of the Study}

The aims of this study are

- To assess fatigue and leg cramps among patients with hemodialysis

- To design and implement intradialytic hemodialysis exercises program to minimize fatigue and leg cramps.

- To evaluate the effect of implementing intradialytic hemodialysis exercises program on fatigue and leg cramps.

\section{Research Hypothesis}

Fatigue and leg cramps was minimized after implementation of intradialytic hemodialysis exercises.

\section{Subject \& Methods \\ Research Design}

Pre / posttest was utilized in this study.

\section{Setting:}

The study was be conducted in dialysis unit at Sohag University Hospital.

Subjects :

A sample of 60 patients who undergoing hemodialysis with peripheral vascular access aged from 18-65 years old.

Tools

Data was collected by using four tools:

Tool(I): Structured Interview Questionnaire sheet It was developed by the researcher to collect the necessary data of this study. This tool was consist of two parts:

Part (1) :Sociodemographic data: it include patient's age, gender, level of education, occupation and marital status.

Part (2) : Medical data: includes duration of hemodialysis treatment, number of session per week, period of experience cramps, location of muscle cramps. muscles involved in cramps .

Tool (II) : Cramp questionnaire chart and visual analogue scale: Pre/ post test.

The cramp questionnaire chart was developed by (Basemath, 2014) It was designed to assess the level of muscle cramps during hemodialysis, before and after intervention. It contains various features of muscle cramps such as the frequency of muscle cramps, duration of muscle cramps, level of pain, temperature and discomfort which was comprehensively scored as level of muscle cramps ranging from (0-13).

Score Interpretation:

$\begin{array}{ll}0 & \text { No cramps } \\ 1-4 & \text { Mild cramps } \\ 5-8 & \text { Moderate cramps } \\ 9-13 & \text { Severe cramps }\end{array}$

Tool (III) : Fatigue severity scale (FSS) (Shahid et al., 2011) : Pre/ post test ( 2 months ) this tool used to assess fatigue symptoms. It is a questionnaire containing nine statements that explore the severity of fatigue symptoms. The patient is asked to circle a number from 1 to 7 , depending on how appropriate they felt the statement applied to them. As regard fatigue level a low value indicates strongly disagree and a high value indicates strongly agree. Total score was 63.

The score is divided by researcher to three categories mild fatigue ( $36-44)$, moderate fatigue ( $45-53$ ) and sever fatigue ( $54-63$ ).

Tool (IV) : Intradialytic exercise : it include three parts

Part (1): Stretching exercise: is a form of physical exercise in which the calf, gastrocnemius, soleus, hamstring and quadriceps muscles are flexed or stretched to improve the muscle's elasticity, muscle tone and reduce the cramps during hemodialysis at a frequency of twice per session after first hour from starting session. Each session of this exercises program was for 20 minutes.

It is consisted of

- Ankle dorsiflexion

- Soleus stretching

- Gastrocnemius stretching

- Hamstring stretching

- Quadriceps stretching 
Part (2) : Range of motion exercise : is a form of physical exercise in which the shoulder, elbow, , hip and foot are flexed or stretched to improve the muscle's elasticity, muscle tone and reduce the cramps and fatigue during hemodialysis at a frequency of twice per session after first hour from starting session. Each session of this exercises program was for 20 minutes.

Part (3) : Isometric Exercise : are a type of strength training, The contraction of the muscle for three to five seconds and then relaxed at a frequency of five times per session after first hour from starting session .

It is consisted of :

- Close chest press and pull

- Extended chest press

- Overhead press

- Biceps curl

- Stomach extensions

- Quad sets

- A hamstring set

- Hip abductor and adductor.

Ethical Consideration

The study was follow the common ethical guidelines of clinical researches according to the principles of Helsinki Declaration of medical researches. (Helsink, 1996)

Methodology

Phase 1: Preparatory phase

- A review of current, past, local and international related literature in the various aspect of the problems using books, articles, periodicals and magazines was done.

\section{Content validity and reliability}

It was established by 5 expertise (three from the academic internal medicine \& two academic from Medical- surgical nursing staff) who reviewed the tools for clarity, relevance and comprehensiveness and then the tools were designed in their final format and tested for reliability . Reliability of the tool was measured by cronbach's alpha coefficient $(r=0.72)$.

\section{Administrative design}

- An official permission was issued the head of dialysis unit administration at sohag hospital university to conduct the present research.

A pilot study

- A pilot study was carried out in February 2019 to test the feasibility and practicability of the study tools on a group of ( $10 \%) 6$ patients. It has also provided an estimate of the time needed to fill out the tools, no change was done in the assessment sheet, so the six patients selected for the pilot study were included in the main study. The purpose of the pilot study was of three folds:
First : To ascertain the relevance of the tool.

Second: To detect any problem peculiar to the statement clarity that may interfere with the purpose of data collection.

Third :To estimate the time needed to complete the interview schedule.

\section{Phase 2: Implementation phase}

Data were collected at the dialysis unit at Sohag University Hospital during the period from March 2019 to August 2019. The tools were filled through interviewing; the purpose of the study was explained to the patients prior to answering the questions. The study was carried out during morning and afternoon shifts for all patients.

After assessment of the patients by using the Tool I, II and III, All patients received the intradialytic exercises program contents by the researcher herself. Using standardized teaching methods discussion, posters , handout, demonstration and redemonstration Teaching program sessions:

The implemented intradialytic exercise program was conducted through 4 theoretical sessions, the duration of each session was around 20 minutes.

First session : the researcher started by introducing herself to the patients telling them aim of the meeting, orient the patients regarding the intradialytic exercises program, contents of this session include information about anatomy and physiology of urinary system, renal failure, hemodialysis, fatigue and leg cramps.

Second session: Started by summary about what has been discussed in a previous session, objectives of the new session and contents of this session includes range of motion exercises that involves shoulder, elbow, hip, knee, ankle and foot range of motion. The session ended by a summary of its content and feedback from the patients. Many patients were cooperative and interested in a given topic and asked to continue the program.

Third session: started by summary about what has been discussed in previous session, objectives of the new session and contents of this session include; Stretching exercises that involves ankle dorsiflexion, soleus stretching, gastrocnemius stretching, hamstring stretching and quadriceps stretching. The session ended by a summary of its content and feedback from the patients.

Fourth session :Started by summary about what has been discussed in previous session, objectives of the new session and contents of this session include: isometric exercise that involves close chest press and pull, extended chest press, overhead press, biceps curl, stomach extensions, quad sets, a hamstring set and hip abductor and adductor. The session ended by a summary of its content and feedback from the 
patients through discussion and asking questions. All patients obtained a copy of intradialytic exercises booklet.

\section{Phase 3: Evaluation phase}

The end phase of proposal teaching program is the evaluation phase, in which the patient was evaluated after two months by the researcher after implementation of intradialytic exercises through filing the tool II \& III.

\section{Statistical design}

Data entry and statistical analysis were done using SPSS computer program "version 23.0" software.
The data were tested for normality using the Anderson -Darling test and for homogeneity variances prior to further statistical analysis. Categorical variables were described by number and percent $(\mathrm{N}, \%)$. continuous variables described by mean and standard deviation ( Mean , SD ) chi square test used to compare between categorical variables. $\mathrm{T}$ - test used to compare between continuous variables Statistical significance was considered at $\mathrm{P}$-value $<0.05$.

\section{Results}

Table (1): Frequency distribution of sociodemographic characteristics for the patients $(n=60)$.

\begin{tabular}{|c|c|c|}
\hline Variables & $\mathbf{N}$ & $\%$ \\
\hline $\begin{array}{l}\text { 1- Age group } \\
-18-<28 \text { yrs. } \\
-29-<39 \text { yrs. } \\
-39-<50 \text { yrs. } \\
-50-65 \text { yrs. }\end{array}$ & $\begin{array}{c}11 \\
7 \\
25 \\
17\end{array}$ & $\begin{array}{l}18.3 \\
11.7 \\
41.7 \\
28.3\end{array}$ \\
\hline Mean age & & \\
\hline $\begin{array}{l}\text { 2- Sex } \\
\text { - Male } \\
\text { - Female } \\
\end{array}$ & $\begin{array}{l}35 \\
25 \\
\end{array}$ & $\begin{array}{r}58.3 \\
41.7 \\
\end{array}$ \\
\hline $\begin{array}{l}\text { 3- Marital status } \\
\text {-Single } \\
\text {-Married } \\
\text {-Divorce } \\
\text {-Widow or widower }\end{array}$ & $\begin{array}{c}8 \\
50 \\
1 \\
1\end{array}$ & $\begin{array}{c}13.3 \\
83.3 \\
1.7 \\
1.7\end{array}$ \\
\hline $\begin{array}{l}\text { 4- Education level } \\
\text {-Illiterate } \\
\text {-Write and Read } \\
\text {-primary education } \\
\text {-preparatory education } \\
\text {-Secondary education } \\
\text {-University }\end{array}$ & $\begin{array}{c}20 \\
5 \\
4 \\
23 \\
1 \\
7\end{array}$ & $\begin{array}{c}33.3 \\
8.3 \\
6.7 \\
38.3 \\
1.7 \\
11.7 \\
\end{array}$ \\
\hline $\begin{array}{l}\text { 5- Occupation } \\
\text {-Employee } \\
\text {-Farmer } \\
\text {-Worker } \\
\text {-Not work }\end{array}$ & $\begin{array}{c}9 \\
4 \\
8 \\
39\end{array}$ & $\begin{array}{c}15.0 \\
6.7 \\
13.3 \\
65\end{array}$ \\
\hline
\end{tabular}

Table (2) : Frequency distribution of medical data about hemodialysis session for patients $(\mathrm{n}=60)$

\begin{tabular}{|l|c|c|}
\hline \multicolumn{1}{|c|}{ Medical data } & N & \% \\
\hline 1-Numbers of session per week & & \\
\hline -Twice & 1 & 1.7 \\
-Third & 59 & 98.3 \\
\hline 2-Duration of dialysis treatment & & \\
\hline - 1 yr. & 7 & 11.7 \\
$-1-5$ yrs. & 29 & 48.3 \\
-More than 5 yrs. & 24 & 40.0 \\
\hline 3-Muscle cramps occur during & & \\
\hline
\end{tabular}




\begin{tabular}{|l|c|c|}
\hline \multicolumn{1}{|c|}{ Medical data } & N & \% \\
\hline -First hours from session & 2 & 3.3 \\
-Middle hours from session & 6 & 10.0 \\
-last hour from session & 52 & 86.7 \\
\hline 4-Location muscle cramps & & \\
\hline -Right leg & 10 & 16.7 \\
-Left leg & 15 & 25.0 \\
-Both legs & 35 & 58.3 \\
\hline 5-Muscle involved in cramps & & \\
\hline -Hamstring & 2 & 3.3 \\
-Gastrocnemius & 50 & 83.3 \\
-Soleus & 4 & 6.7 \\
-Calf muscles & 4 & 6.7 \\
\hline
\end{tabular}

Table (3): Frequency distribution of cramp questionnaire chart and visual analogue scale for patients pre and post implementation of intradialytic exercises $(n=60)$.

\begin{tabular}{|c|c|c|c|c|c|c|c|}
\hline \multirow{2}{*}{ NO. } & \multirow{2}{*}{$\begin{array}{l}\text { Feature of muscle cramps } \\
\text { Frequency of cramps }\end{array}$} & \multirow[t]{2}{*}{ Scores } & \multicolumn{2}{|c|}{$\begin{array}{c}\text { Pre- } \\
\text { excercise }\end{array}$} & \multicolumn{2}{|c|}{$\begin{array}{c}\text { Post- } \\
\text { exercise }\end{array}$} & \multirow[t]{2}{*}{ Sig. } \\
\hline & & & $\mathbf{N}$ & $\%$ & $\mathbf{N}$ & $\%$ & \\
\hline 1 & Does not occur & 0 & 0 & 0.0 & 28 & 46.7 & \multirow{3}{*}{$0.001 *$} \\
\hline 2 & Cramps occur less than 3 times /hour & 1 & 49 & 81.7 & 32 & 53.3 & \\
\hline 3 & Cramps occur more than 3 times /hour & 2 & 11 & 18.3 & 0 & 0.0 & \\
\hline II & Duration of the cramps & & & & & & \\
\hline 1 & Cramps does not occur & 0 & 0 & 0.0 & 27 & 45.0 & \multirow{3}{*}{$0.001^{*}$} \\
\hline 2 & Cramps lasts for less than 5 minutes & 1 & 9 & 15.0 & 33 & 55.0 & \\
\hline 3 & Cramps lasts for more than 5 minutes & 2 & 51 & 85.0 & 0 & 0.0 & \\
\hline III & Level of pain ( VAS) & & & & & & \\
\hline 1 & No pain & 0 & 0 & 0.0 & 0 & 0.0 & \multirow{4}{*}{$0.001 *$} \\
\hline 2 & Pain 1-3 & 1 & 0 & 0.0 & 21 & 35.0 & \\
\hline 3 & Pain 4-6 & 2 & 2 & 3.3 & 39 & 65.0 & \\
\hline 4 & Pain 7-10 & 3 & 58 & 96.7 & 0 & 0.0 & \\
\hline IV & Temperature - Leg & & & & & & \\
\hline 1 & Warm & 0 & 3 & 5.0 & 47 & 78.3 & \multirow{3}{*}{$0.001 *$} \\
\hline 2 & Cold & 1 & 49 & 81.7 & 13 & 21.7 & \\
\hline 3 & Cold /clammy & 2 & 8 & 13.3 & 0 & 0.0 & \\
\hline $\mathbf{V}$ & Discomfort & & & & & & \multirow{6}{*}{$0.001 *$} \\
\hline 1 & No cramps & 0 & 0 & 0.0 & 1 & 1.7 & \\
\hline 2 & Perceptible & 1 & 1 & 1.7 & 20 & 33.3 & \\
\hline 3 & Sensitive & 2 & 4 & 6.7 & 39 & 65.0 & \\
\hline 4 & Painful & 3 & 17 & 28.3 & 0 & 0.0 & \\
\hline 5 & Unbearable & 4 & 38 & 63.3 & 0 & 0.0 & \\
\hline
\end{tabular}




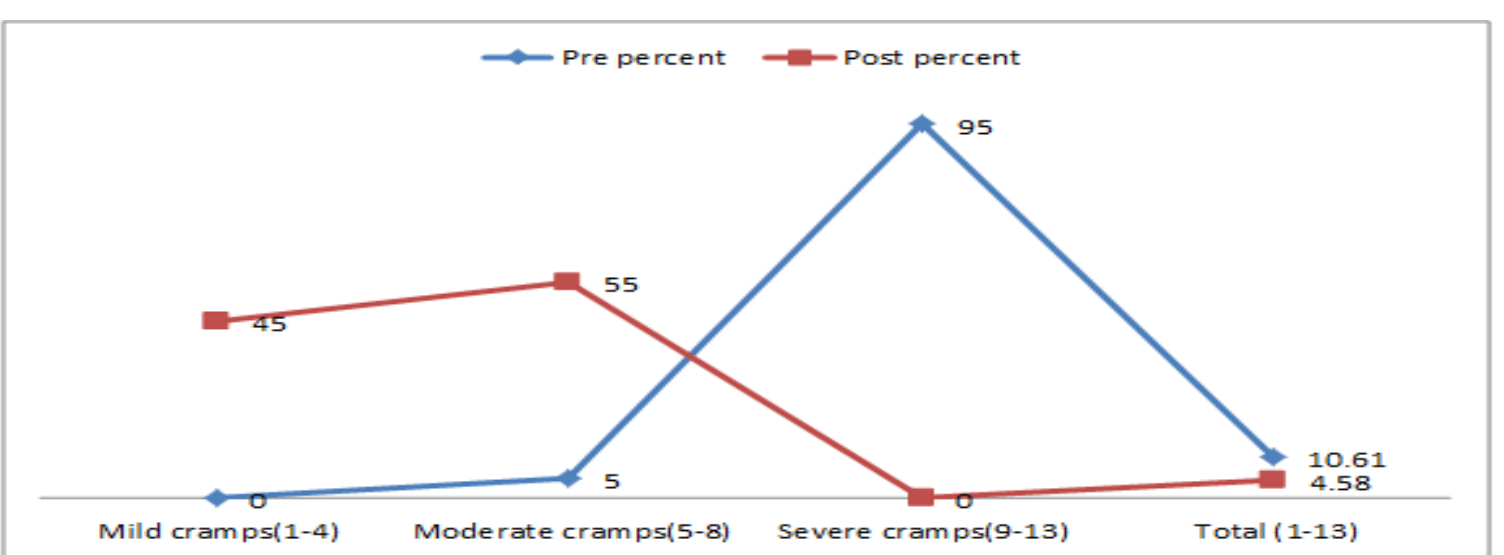

Figure (1) Feature of muscle cramps Frequency distribution of total feature of muscle cramps pre and post implementation intradialytic exercise $(n=60)$.

Table (4): mean average score of measurement of fatigue severity scale for patients pre and post implementation of intradialytic exercise $(n=60)$.

\begin{tabular}{|c|c|c|c|c|}
\hline Fatigue severity scale total score (1- 7 dgree) & Study case & Mean & Std. Deviation & P.value \\
\hline \multirow[t]{2}{*}{ 1-My motivation is lower when I am fatigued } & pretest & 6.26 & 1.02 & $0.001 * *$ \\
\hline & posttest & 3.93 & 0.66 & $0.001 * *$ \\
\hline \multirow[t]{2}{*}{ 2-Exercise brings on my fatigue. } & pretest & 6.20 & 0.98 & $0.001 * *$ \\
\hline & posttest & 3.86 & 0.72 & $0.001 * *$ \\
\hline \multirow[t]{2}{*}{ 3-Iam easily fatigued. } & pretest & 6.18 & 1.06 & $0.001 * *$ \\
\hline & posttest & 4.06 & 0.60 & $0.001 * *$ \\
\hline \multirow[t]{2}{*}{ 4-Fatigue interferes with my physical functioning. } & pretest & 6.08 & 1.07 & $0.001 * *$ \\
\hline & posttest & 4.31 & 0.56 & $0.001 * *$ \\
\hline \multirow[t]{2}{*}{ 5-Fatigue causes frequent problems for me. } & pretest & 6.23 & 1.03 & $0.001 * *$ \\
\hline & posttest & 4.13 & 0.56 & $0.001 * *$ \\
\hline \multirow{2}{*}{$\begin{array}{l}\text { 6-My fatigue prevents sustained physical } \\
\text { functioning. }\end{array}$} & pretest & 6.20 & 1.03 & $0.001 * *$ \\
\hline & posttest & 4.31 & 0.67 & $0.001 * *$ \\
\hline \multirow{2}{*}{$\begin{array}{l}\text { 7-Fatigue interferes with carrying out certain } \\
\text { duties and responsibilities }\end{array}$} & pretest & 6.16 & 1.04 & $0.001 * *$ \\
\hline & posttest & 4.16 & 0.66 & $0.001 * *$ \\
\hline \multirow[t]{2}{*}{ 8-Fatigue is among my most disabling symptoms. } & pretest & 6.16 & 1.04 & $0.001 * *$ \\
\hline & posttest & 4.53 & 0.65 & $0.001 * *$ \\
\hline \multirow{2}{*}{$\begin{array}{l}\text { 9-Fatigue interferes with my work, family, or } \\
\text { social life. }\end{array}$} & pretest & 6.10 & 1.05 & $0.001 * *$ \\
\hline & posttest & 4.26 & 1.03 & $0.001 * *$ \\
\hline
\end{tabular}

Table (5): Total score of fatigue severity scale for patients pre and post implementation of intradialytic exercise. $(n=60)$.

\begin{tabular}{|c|c|c|c|c|c|c|}
\hline \multirow[t]{2}{*}{ Total Fatigue severity scale } & \multirow[t]{2}{*}{ Scores } & \multicolumn{2}{|c|}{ Pre } & \multicolumn{2}{|c|}{ Post } & \multirow[t]{2}{*}{ P.value } \\
\hline & & $\mathbf{N}$ & $\%$ & $\mathbf{N}$ & $\%$ & \\
\hline Mild fatigue & $36-44$ & 2 & 3.3 & 53 & 88.3 & \multirow{4}{*}{$0.001 *$} \\
\hline Moderate fatigue & $45-53$ & 19 & 31.7 & 7 & 11.7 & \\
\hline Sever fatigue & $54-63$ & 39 & 65.0 & 0 & 0.0 & \\
\hline Total & 63 & \multicolumn{2}{|c|}{$55.60 \pm 7.93$} & \multicolumn{2}{|c|}{$37.60 \pm 3.33$} & \\
\hline
\end{tabular}


Table (6): Correlation between fatigue severity scale and cramp questionnaire scale.

\begin{tabular}{|l|c|c|c|}
\hline \multicolumn{2}{|c|}{ Correlations } & $\begin{array}{c}\text { Pre -test } \\
\text { cramp question }\end{array}$ & $\begin{array}{c}\text { Post-test } \\
\text { cramp question }\end{array}$ \\
\hline \multirow{2}{*}{ Total fatigue severity score } & Pearson Correlation & .060 & $.346^{* *}$ \\
\cline { 2 - 4 } & Sig. (2-tailed) & .647 & .007 \\
\cline { 2 - 4 } & $\mathrm{N}$ & 60 & 60 \\
\hline
\end{tabular}

Table (1): Showed that the socio-demographic characteristics for patients. The mean age of the patients was $43.80 \pm 12.089$ (range 18-65) . As regard age two fifth $(41.7 \%)$ of the patients were in age (40$50 \mathrm{yrs}$.).As regard gender, more than half of patients $(58.3 \%)$ were male. It was found that majority of patients $(83.3 \%)$ were married, as regard educational level two fifths of the patients $(38.3 \%)$ were preparatory education and as regard occupation, two third of the patients $(65 \%)$ were not work.

Table (2): Illustrated that there was more than two fifths of patients $(48.3 \%)$ the duration of dialysis were 1-5 years. In relation to number of session perweek, vast majority of patients $(98.3 \%)$ were 3 time per-week. Also this table enumerated that majority of the patients $(86.7 \%)$ were experienced muscle cramps during the last hour of hemodialysis. As regard location of muscle cramps, More than half of patients (58.3\%) experienced muscle cramps in both the legs. As regard muscle involved in cramps, majority of patients $(83.3 \%)$ experienced muscle cramps in Gastrocnemius muscle.

Table(3): Showed that before intradialytic exercise majority of patient's cramps $(81.7 \%)$ occur less than 3 times /hour. After intradialytic exercise, more than half $(53.3 \%)$ experienced cramps occur less than 3 times /hour.

Regarding Duration of the cramps the majority of patient's cramps $(85.0 \%)$ lasts for more than 5 minutes. before intradialytic exercise, more than half of patient's cramps $(55.0 \%)$ lasts for less than 5 minutes, after intradialytic. As regard level of pain , vast majority of patient's pain $(96.7 \%)$ score were 7 10 before intradilytic exercise, while after intradialytic exercise, two third of patient's pain (65.0 $\%$ ) score were 4-6.

Regarding temperature - leg, majority of patients $(81.7 \%)$ their leg were cold before intradilytic exercise. While after intradialytic exercise, three quarters of patients $(78.3 \%)$ their leg were warm . As regard discomfort, two third of patients $(63.3 \%)$ were unbearable before intradilytic exercise. While after intradialytic exercise, two third of patients $(65.0 \%)$ were Sensitive.
There were statistical significance differences as regard cramps questionnaire chart \& visual analogue scale pre \& post implementation of intradialytic exercises.

Figure (1): Showed that there were statistical significance difference as regard total feature of muscle cramps pre and post implementation of intradialytic exercises.

Table (4): This table showed that there were a statistical significant different found in fatigue severity scale in posttest comparing to pre- test.

Table (5): this table mentioned that there was statistical significance differences founded in total score of fatigue severity scale for patients pre $\&$ post implementation of intradialytic exercises.

Table (6): Showed that there was positive correlation between fatigue severity scale and cramp questionnaire scale after 2 months of intradialytic excercises application.

\section{Discussion}

This study was conducted to evaluate the effectiveness of intradialytic exercises on fatigue and muscle cramps among patients undergoing hemodialysis.

Intra dialytic exercise improves exercise adoption and adherence, it is performed safely, and is feasible to administer. Moreover, intra dialytic exercise can improve solute removal, hemodialysis adequacy, intra dialytic protein synthesis, muscular strength, peak oxygen consumption, nutritional status and quality of life.(Merline et al., 2018).

The distribution of patients according to their demographic variables revealed that two fifth of the patients were in age from fourty to fifty years. It was found that majority of patients were married and more than half of patients were male.

The Present study was supported by (Ibrahim \& Mokhtar, 2018) who conducted a study to assess Leg Exercise: Effect on Reducing Fatigue and Improving Activities of Daily Living For hemodialysis patients in the dialysis unit at Aswan University Hospital. The result revealed that most patients were married and their age were 40-50 years. Regarding to gender, this result disagrees with 
(Bahgat et al., 2016) who reported that more than half of patients were female.

Concerning their educational level, the current study results revealed that two fifths of patients were preparatory education. This result disagrees with (Bayoumi \& Al wakeel, 2015) who reported that half of patients were read \& write.

As regards occupation of the patients, the present study mentioned that two third of patients were not work ,This result similar to (Bayoumi \& Alwakeel, 2015) who reported that magority of patients were not work.

Regarding to numbers of session per week the current study results revealed that vast majority of patients were doing dialysis three times a week. This result disagrees with (Elavally et al., 2017) who reported that one fifth of patients were doing dialysis three times a week

Regrading duration of dailysis, This study illustrated that there was more than two fifths of patients were one to five years, This result disagrees with (Lekha et al., 2017) who reported that three quarters of patients underwent hemodialysis treatment for more than four years.

Also, this study show that majority of the patients were experienced muscle cramps during the last hour of hemodialysis. As regard location of muscle cramps, more than half of patients experienced muscle cramps in both the legs. As regard muscle involved in cramps, majority of patients experienced muscle cramps in Gastrocnemius muscle .

The present study was supported by (Lekha et al., 2017) who reported that majority of the patients were experienced muscle cramps during the last hour of hemodialysis and more than half of patients experienced muscle cramps in both the legs and this study disagree with (Naylor \& Young, 2004) who report that majority of patients experienced muscle cramps in calf muscles.

The present study results indicated that there is effectiveness in performing intradialytic exercises on prevention and reduction of muscle cramps during haemodialysis. The current study findings revealed that after intradialytic exercise half of patients doesn't experience muscle cramps. this result similar to (Ahmed et al., 2007) who reported that two third of patients did not experience muscle cramps during the post test.

Regarding level of pain vast majority of patients were sever pain before intradialytic excercises. this result disagree with (Ahmed et al., 2007) who reported that one fifith of patients were sever pain before nursing instructions. After intradialytic exercise, more than half of patients were moderate pain, this result disagree with (Salem and Elhadary, 2017) who reported that two third of patients were mild pain after leg stretching exercises.

Regarding temperature - leg, majority of patients their leg were cold before intradialytic exercise. While after intradialytic exercise, three quarters of patients their leg were warm and regarding discomfort, two third of patients were unbearable before intradialytic exccecise, while after intradialytic exercise, two third of patients were sensitive. This result disagree with ( lekha et al., 2017) who reported that during the pretest half of the patients experinced cold and clammy temperture but agree in after performing the intradialytic streching excercises the postest show that more than half of the patients experinced warm temperature. But agree in discomfort, half of patients were unbearable before intradialytic exccecise, but disagree after intradialytic exercise, two third of patients were no cramps.

Regarding feature of muscle cramps, this study show that before intradialytic exercise vast majority of patients were severe cramps. while after intradialytic excercise, more than half of patients were moderate cramps. this similar to (Vimala., 2018 ) who reported that before intra dialytic stretching exercise majority of patients were sever cramps before and after intradialytic stretching exercise two fifths of patients were moderate cramps. The present study show that a statistical significant different was found in fatigue in posttest comparing to pre- test assessment . this result supported by (Soliman., 2015) who reported that there was a statistically significant differences in fatigue score pre and posttest .

The present study show that two third of patients were suffered from severe fatigue before intradialytic exercises. while, majority of patients were suffered from mild fatigue after intrdialytic exercise application. this result disagree with (Jose et al., 2014) who reported that during pretest two third of patients had moderate level of fatigue and one third of patients had severe fatigue and in the posttest one third of patients had mild fatigue and half of patients had moderate fatigue.

Finally, based on this study results; there was positive correlation between fatigue severity scale and cramp questionnaire scale after 2 months of intradialytic excercises application. My interpretation of this is that fatigue may be prime cause of muscle cramps.

\section{Conclusion}

The present study was done to evaluate effect of intradialytic hemodialysis exercises on fatigue and leg cramps The findings of the study revealed that there were statistical significance differences as regard cramps questionnaire chart and visual 
analogue scale pre \& post intradialytic exercises. There were statistical significance differences found in fatigue severity scale in posttest comparing to pretest. There was positive correlation between fatigue severity scale and cramp questionnaire scale.

\section{Recommendation: The study Recommended that}

1- Staff nurses have to be trained to implement intradialytic exercise during hemodialysis to reduce the level of fatigue $\&$ muscle cramps.

2- Intradialytic exercises can be adapted as a procedure to the patients undergoing hemodialysis.

3- The study can be focused on patients with newly diagnosed to identify the severity of fatigue.

\section{References}

1. Ahmed, A., Mohamed, M., Zead, S., (2007): Impact of stretching exercises protocol on reduction of muscle cramping during haemdialysis, among chronic renal failure patients. Australian Medical Journal.5(3),73-76.

2. Artom, M., Moss-Morris, R., Caskey, F., \& Chilcot, J., (2014): Fatigue in advanced kidney disease. Kidney international, Pp :(497-505).

3. Bahgat, Z., Bahgat \& H., El-azazy (2016): "The effect of fatigue on daily living activities for adults undergoing hemodialysis."IOSR Journal of Nursing and Health Science 5(3): 8289.

4. Basemath, S., (2014): Devlopment and testing of Cramp questionnaire chart.

5. Bayoumi, M., \& Alwakeel, J., (2015): Impacts of Exercise programs on Hemodialysis Patients' Quality of Life and Physical Fitness, Quality in primary care Journal, 23(6):9.

6. Caplin B., Kumar S., Davenport A., (2017): .Patients' perspective of haemodialysisassociated symptoms. Nephrol Dial Transplant ;26(8):2656-63.

7. Damasiewicz M., Polkinghorne K., (2017): Intra-dialytic hypotension and blood volume and blood temperature monitoring. Nephrology (Carlton) 2011;16:13-8.

8. El-Arbagy, A., Yassin, Y., \& Boshra, B., (2016): Menoufia Medical Journal, Study of prevalence of end-stage renal disease, Volume : 29, PP : 222-227.

9. Elavally, S., Rathinasamy, E., \& Venkatasalu, M., (2017): Effect of Prophylactic Intra-dialytic Stretching Exercises (IDSE) on Muscle Cramps among Patients Undergoing Hemodialysis: A Single Blind experimental Study, Brunei Darussalam Journal of Health, (1): 50-62.

10. Hall, Y., Larive, B, Painter, P., Kaysen, G., Lindsay, R., \& Nissenson, A., (2015): Effects of six versus three times per week hemodialysis on physical performance, health, and functioning: Frequent Hemodialysis Network (FHN) randomized trials.

11. Helsink, H., (1996): World medical association declaration of Helsiniki.PP:17.

12. Horigan, A., Schneider, S., Docherty, S., \& Barroso, J., (2013): The experience and selfmanagement of fatigue in hemodialysis patients. Nephrology nursing journal: Journal of the American Nephrology Nurses' Association, Pp :(113).

13. Ibrahim, M., \& Mokhtar, I., (2018): Leg Exercise: Effect on Reducing Fatigue and Improving Activities of Daily Living For Hemodialysis Patients, IOSR Journal of Nursing and Health Science, Volume 7, Issue 3, PP 1119.

14. Isaac, S.,\& Priya, B., (2016): Impact of intradialytic exercise on fatigue \& leg pain among hemodialysis patient . International Journal of Medicine and Health Profession Research.

15. Jose, S., Devi, B., \& Victoria, E., (2014): Effectiveness of intradialytic leg exercise((ILE) on fatigue and activities daily living among patients subjected to hemodialysis, Journal of sciene, Vol:4, Issue: 1.

16. Lekha, J., Abraham, E., \& Malarvizhi, G., (2017): Effectiveness of Intradialytic Stretching Exercises on Prevention and Reduction of Muscle Cramps among Patients undergoing Haemodialysis at PSG Hospitals Coimbatore, Journal of Nursing and Health Science, Volume 6, Issue 2, PP 47-53.

17. Merline, M., Deepa, R., \& Nirmala, T., (2018): Effect of intradialytic exercise on fatigue among patients undergoing hemodialysis, International Journal of Applied Research, 4(4): PP: 394-397.

18. Naylor, J., Young J., (2004): A general population survey of rest cramps. Age Ageing. Australian Journal of Nephrology. 23(5),418420.

19. Paluchamy' T., Vaidyanathan, R., (2018): Effectiveness of intradialytic exercise on dialysis adequacy, physiological parameters, biochemical markers and quality of life - A pilot study,Saudi journal of kidney disease and transplantation, Vol : 29, Issue : 4, PP : 902910 
20. Park, S., \& Jung, T., (2017): Intradialytic Exercise Programs for Hemodialysis Patients. Chonnam Medical Journal ;47:61-65.

21. Salem, S., \& Elhadary, S., (2017): Effectiveness of Intra-dialytic Stretching Exercises on Leg Muscle Cramp among Hemodialysis Patients, Journal of Nursing and Health Science, Volume 6, Issue 2, PP: 47-53.

22. Salhab, N., Karavetian, M., Kooman, J., Fiaccadori, E., \& El Khoury, C., (2019): Journal of Nephrology, Effects of intradialytic aerobic exercise on hemodialysis patients: a systematic review and meta-analysis, Volume :32, Issue: 4, pp: 549-566.

23. Shahid, A., Wilkinson, K., Marcu, S., \& Colin M., (2011): Devlopment and testing of the Fatigue severity scale(FSS)

24. Soliman, H., (2015): Effect of intradialytic exercise on fatigue, electrolytes level and blood pressure in hemodialysis patients: A randomized controlled trial , Journal of Nursing Education and Practice, Vol. 5, No. 11, URL: http://dx.doi.org/10.5430/jnep.v5n11p16 .

25. Vimala, A., (2018): Effectiveness of Intradialytic Stretching Exercises on Reduction of Muscle Cramps Among Patients Undergoing Haemodialysis at Sundaram Hospital Trichy, Approved by the Research Committee.

26. Wanek, M., Horn, E., Elapavaluru, S., Baroody, S., \& Sokos G., (2015): Safe use of hemodialysis for dabigatran removal before cardiac surgery. 